\title{
CORRELATION BETWEEN MORPHOLOGICAL AND FRACTION SIZE OF INTERMETALLIC ON FLUIDITY OF AL-11\%SI ALLOY WITH FE ADDITION
}

\author{
IS PRIMA NANDA DAN BAMBANG SUHARNO \\ Department of Metalurgi and Material, Faculty of Engineering University of Indonesia \\ E-mail: isprimananda@yahoo.com
}

\begin{abstract}
Intermetallic morphology influence on the fluidity of alloys Al-11\% Si. From the experiments, fluidity in the alloy Al-11\% Si were added $0.6,0.8$, and $1.0 \% \mathrm{Fe}$, it was found that the higher the Fe content is added to the values decreasing fluidity. On addition of $1 \% \mathrm{Fe}$ provides the longest phase of intermetallic $50.2 \mu \mathrm{m}$, while the shortest intermetallic phase is given by the addition of $0.6 \% \mathrm{Fe} 21.3 \mu \mathrm{m}$. In the alloy Al-11\% Si with the addition of Fe are generally higher and higher, would produce intermetallic area fraction increased significantly. On addition of $0.6 \%$ Fe intermetallic area fraction of $1.01 \%$, while the addition of $0.8 \%$ and $1 \% \mathrm{Fe}$ Fe each area fraction $1.16 \%$ and $2.26 \%$.
\end{abstract}

Key words: morphology influence, fluidity of alloys $\mathrm{Al}-11 \% \mathrm{Si}$

\section{INTRODUCTION}

In the automotive industry recently has occurred transitional material using an iron based alloy or plastic-based material of aluminum alloy. The use of metal materials such as aluminum automotive components based on the presence of one savings on fuel used in a vehicle. Meanwhile, issues facing the automotive components industry this time is to obtain a high purity aluminum material and free from impurities which are merugikan against aluminum alloy. One of the impurity elements contained in aluminum is the element Fe. There is an element of $\mathrm{Fe}$ in the aluminum lower mechanical properties (ductility) and castability especially capable of flow properties or fluiditasnya. The higher content of Fe in the aluminum silicon alloy can reduce the fluidity of the alloy (Villeneuv, et.al, 1999). The presence of Fe intermetallic phase will present on silicon aluminum alloys. This intermetallic phase in large quantities is not desirable. Intermetallic phase act as stress concentration so that the material is brittle. Source of the existence of iron in the casting process of smelting equipment and derived from the remelt scrap (John, 2000). The presence of iron can not be removed from the aluminum, but the damaging effects can be reduced by neutralization or modification of the method.

In aluminum alloys are generally formed intermetallic phase is intermetallic phase $\mathrm{Al}_{8} \mathrm{Fe}_{2} \mathrm{Si}$ or $\mathrm{Al}_{12} \mathrm{Fe}_{3} \mathrm{Si}_{2}(\alpha$-AlFeSi) which is shaped like a chinesescript and $\mathrm{Al}_{5} \mathrm{FeSi}$ or $\mathrm{Al}_{9} \mathrm{Fe}_{2} \mathrm{Si}_{2}(\beta$-AlFeSi) which is shaped like a rough needles and the numbers will more and more as the addition of Fe content. $\beta$-phase intermetallic AlFeSi have a form very sharp and very high angle with the matrix (highly faceted) so as to produce a very weak bond with the matrix of aluminum so that it can disrupt the flow of molten aluminum during the freezing process, limiting feedability and cause the formation of porosity and defects in the foundry (Kral, 2004). The higher content of $\mathrm{Fe}$ in the alloy $\mathrm{Al}-11 \% \mathrm{Si}$ will increase the size of the thickness and length of the morphology of intermetallic $\beta$-AlFeSi.

Value fluidity alloys are generally used as a measure of the ability to fill a mold from liquid metal. This is an important factor in casting, in particular to avoid the flaws that often occurs on the body cast. Factors affecting the fluidity values basically consist of the intrinsic fluid and casting conditions. Intrinsic viscosity fluid composed of the surface tension, characteristic of the surface oxide layer on the surface, the content of inclusions, and material composition, while the condition factor of the casting consists of molds, mold design, surface characteristics of mold, printed material, casting speed, dynamics and physical measurements fluid from the system. Fluidity value can be measured using test equipment fluidity. Various methods of measurement of fluidity has been developed by some researchers, such as spiral method, spiral box and cross-channel method (Ninh, et.al, 2005). In this research designed a method of vacuum fluidity test apparatus (vacuum fluidity test) which has the advantage of measuring the fluidity of the metal (Nanda,2006). 


\section{METHODOLOGY}

To see the effect of Fe in the alloy $\mathrm{Al}-11 \% \mathrm{Si}$ on the formation of intermetallic (morphology and area fraction of intermetallic) and their correlation with the value of fluidity, so the additional engineering $0.6,0.8$, and $1.0 \% \mathrm{Fe}$ master alloy on $\mathrm{Al}-11 \% \mathrm{Si}$. The added elements such as iron alloy $\mathrm{Al}-80 \% \mathrm{Fe} 95 \% \mathrm{Fe}$ with the effectiveness that need the additional weight of alloy $\mathrm{Al}-80 \% \mathrm{Fe}$ by $5 \%$ in each composition the addition of Fe.

Before the melting process, first material balance calculation to obtain the desired chemical composition during melting. Smelting furnace is done by using coal fuel briquettes and assisted with the burner. Master alloy $\mathrm{Al}-11 \%$ Si which has been cut and weighed gradually incorporated into the 1400 capacity kowi gr. After the master alloy melt, carried out to tie the fluxing impurities such as oxides or other impurities by sowing cover of flux on the surface of molten aluminum. Elements of iron added in the form of small slabs of Al-80Fe alloys are first crushed into powder and then wrapped with aluminum foil so that $\mathrm{Fe}$ can be dissolved completely during the melting process at temperatures above $8000 \mathrm{C}$. The process is done with the plunger for 5 minutes. Before testing the fluidity prior degassing process is carried out using argon gas for one minute to clean the gases dissolved in the liquid fluidity aluminum. Cast test was conducted at a temperature of $660,680,700$, and $720^{\circ} \mathrm{C}$, each of which is two times decision to obtain a representative value. Fluidity test method uses vacuum fluidity apparatus shown in Figure 1.

Method of vacuum fluidity test apparatus consists of three systems of pneumatic systems, vacuum systems and electrical systems. Electric system produces power that is transformed into a vacuum pump with a membrane system. Vacuum system serves to provide a certain vacuum pressure $(8 \mathrm{inHg})$, stabilized by a vacuum chamber. Pneumatic system

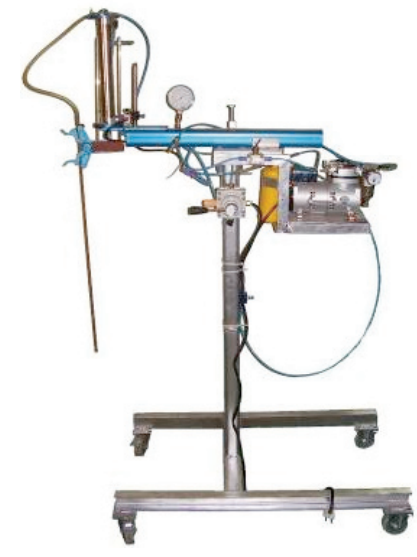

Figure 1. Fluidity test apparatus Vacuum Method used to move the pipes with the stability of an accurate measure because of the speed of rise and fall of this pneumatic constant. When the measuring tube into krusibel (in this case the liquid metal), automatic vacuum valves open simultaneously so that the molten aluminum into the measuring pipe in accordance with a constant pressure. The process of withdrawal of liquid aluminum brief ( \pm 3 seconds). Long fluidity can be seen visually from the change in color on copper pipe.

Microstucture observation was conducted using Scanning Electron Microscope (SEM) LEO 420 equipped with Energy-dispersive Spectroscopy. Intermetallic thickness and length measurement using the existing facilities at the SEM machine. By using SEM/EDX is expected to identify the matrix of aluminum silicon, silicon structure, and EDX testing intermetallic phase in a point/spot on the sample produces an output in the form of the percentage of elements (not compounds such as those generated from testing XRD). While widely used calculation software PICSARA fraction.

\section{RESULTS \& DISCUSSION}

Effect of Fe addition on the fluidity of alloys Al11\% Si In Figure 2 below shows that the higher the Fe content is added to the alloy $\mathrm{Al}-11 \% \mathrm{Si}$, will decrease the value of fluidity in each temperature condition. Iron is an element that has very low solubility in solid aluminum ( $~ 0.05 \%$, at equilibrium). Addition of iron content more than $0.05 \%$ will cause a lot of iron which are insoluble in the matrix and will remain in the molten aluminum until the end of the freeze, which then precipitates as a second phase intermetallic. This intermetallic phase will reduce the value of fluidity of the alloy, in this case because intermetallic phase

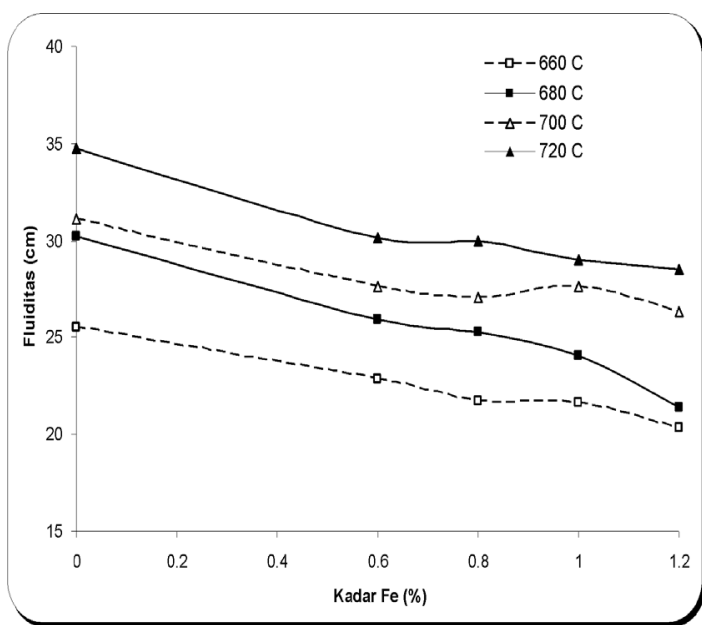

Figure 2. The relationship between the addition of Fe to the value of fluidity in every condition of temperature alloy castings of $\mathrm{Al}-\mathrm{Si} 11 \%$. 
has a greater density, thereby increasing the viscosity of liquid metal and could reduce the flow or fluidity value.

This can be explained by inhibition of the flow scheme of liquid aluminum alloys by intermetallic phases as shown in Figure 3. From this figure shows that the intermetallic phase formed between the arms of the dendrites would prevent interdendritik channel, so it can charge for incoming flow of molten metal into molds. Intermetallic phase formed increasingly large, will lead the process of feeding (charging molten aluminum into molds) was getting annoyed, so the fluidity of Al-Si alloys decreases.

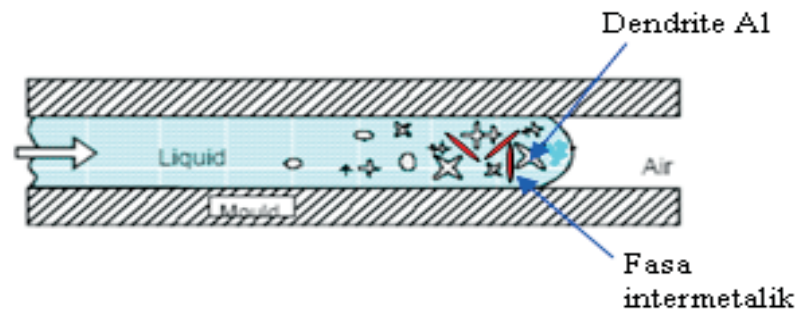

Figure 3. Inhibition scheme flow of liquid aluminum alloys by intermetallic phases [7]

Decline in value of fluidity due to elevated levels of $\mathrm{Fe}$ is not only due to the increased viscosity of the liquid metal value, but it is caused by the increase in the number of intermetallic phases and changes in the morphology of the intermetallic. Micro Structure Analysis of Al-11\% Si Using SEM/EDX Testing and microstructure analysis using SEM equipment (Scanning Electron Microscope) aims to identify the phase-phase formed. Identification of phase-phase microstructure is formed on the photo used EDX testing, by means of shooting at each point/spot (the matrix of aluminum, silicon and intermetallic structures). Results indicated the shooting as shown in Figure 4. from the observation with SEM/EDX, microstructure of the matrix aluminum alloy is dark, fine needle-shaped silicon structure and it's color of ashes, and the plate-shaped intermetallic phase/white rough needle

Analysis of intermetallic morphology (thickness and length) and area fraction of intermetallic on the microstructure of Alloy Al-11\% Si. Testing and quantitative analysis of alloys Al-11\% Si to explain the size (length and thickness) intermetallic using facilities found on the SEM equipment Effect of Fe addition on the morphology of intermetallic phase in the alloy $\mathrm{Al}-11 \%$ Si can be seen in Table 1 and Figure 5. From Table 1 and Figure 5 shows that the greater the Fe content which is added the intermetallic thickness and length is also greater
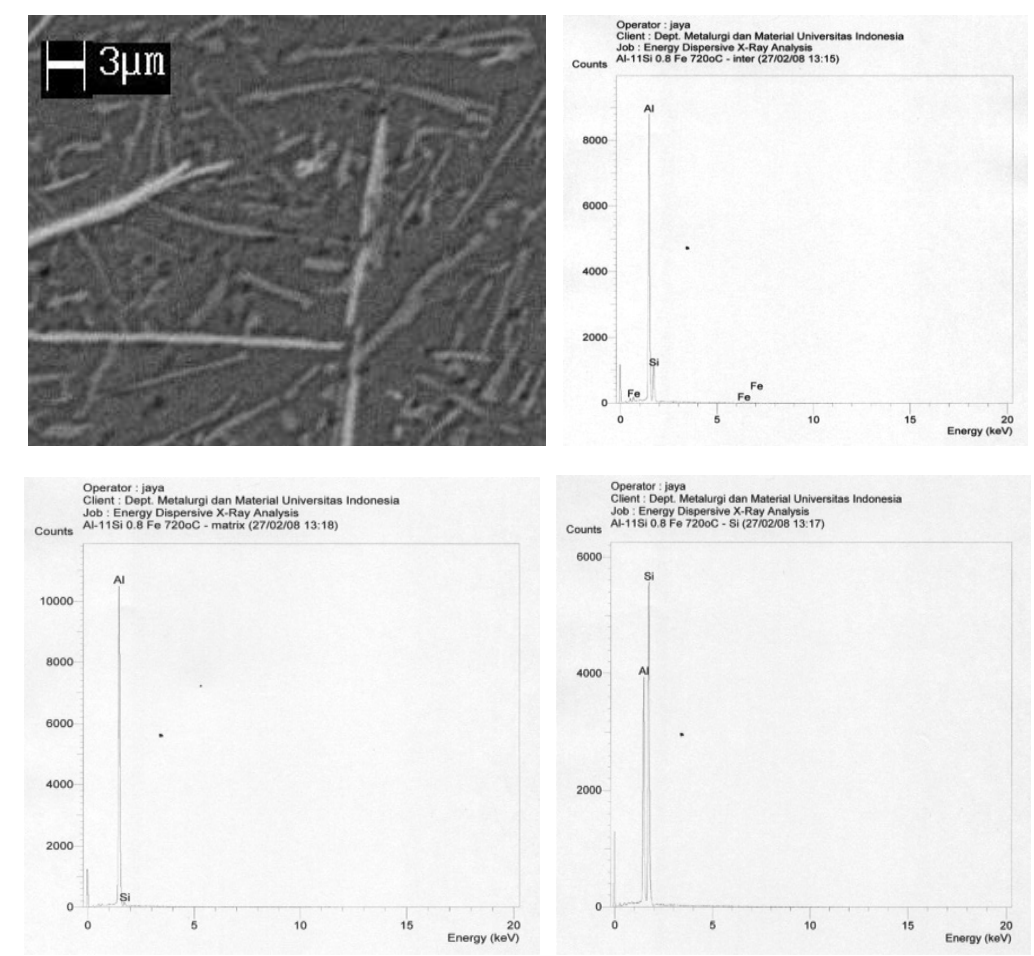

Figure 4. (A) SEM Alloy Al-11\% Si-1, 0\% Fe with 0,5\% HF etching. EDX results of (b) Intermetallic. (C) the matrix $\mathrm{Al}$ (d) eutectic silicon. 
Table 1. The relationship between the percentage of Fe content with the thickness and length

\begin{tabular}{ccc}
\hline$\% \mathbf{F e}$ & $\begin{array}{c}\text { Intermetalic } \\
\text { Thickness }(\mu \mathbf{m})\end{array}$ & $\begin{array}{c}\text { Intermetalic Length } \\
(\mu \mathbf{m})\end{array}$ \\
\hline 0,6 & 1,1 & 21,4 \\
0,8 & 1,6 & 32,2 \\
1,0 & 1,6 & 50,2 \\
\hline
\end{tabular}

Based on the results of calculations can be seen that the eutectic composition of aluminum $(\mathrm{Al}-11 \% \mathrm{Si})$ with the addition of $0.6 \% \mathrm{Fe}$; the length reached 21.4 $\mu \mathrm{m}$ thick intermetallic formed reaches $1.1 \mu \mathrm{m}$ On the addition of $0.8 \% \mathrm{Fe}$; size intermetallic phase grew by $1.6 \mu \mathrm{m}$ thick and the length of $32.2 \mu \mathrm{m}$. On addition of $1.0 \% \mathrm{Fe}$, intermetallic thickness remained 1,6 $\mu \mathrm{m}$ in length but significantly increased the amount of $50.2 \mu \mathrm{m}$.

(a)

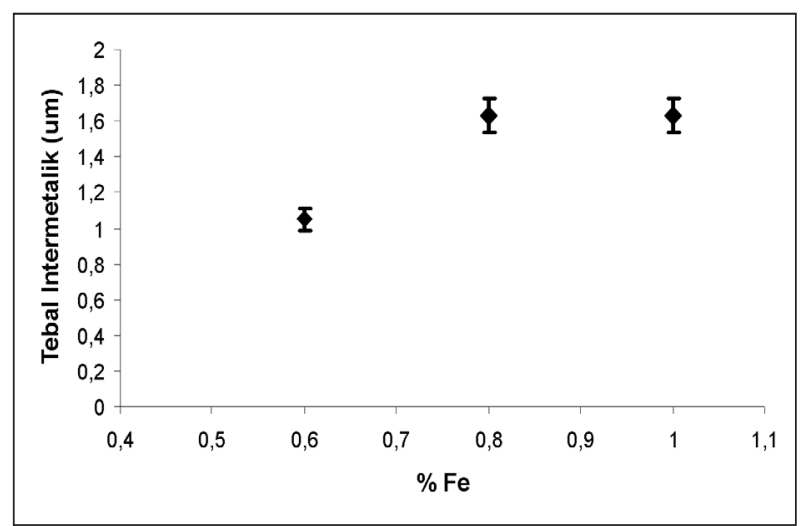

(b)

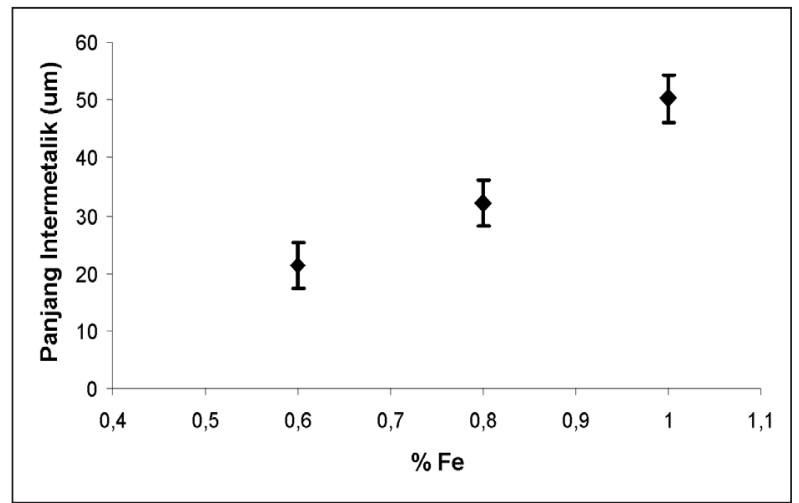

Figure 5. The relationship between the percentage of Fe content by (a) thick and (b) the length of intermetallic formed at eutectic AlSi.

Changes in the size of these intermetallic alloys will affect the value of fluidity of $\mathrm{Al}-11 \% \mathrm{Si}$, where the greater the size of the intermetallic alloy will reduce the value of fluidity in each conditions (see graph fluidity test in Figure 2). Calculation of area fraction of intermetallic phase in the alloy $\mathrm{Al}-11 \% \mathrm{Si}$ is shown in Figure 6 below:

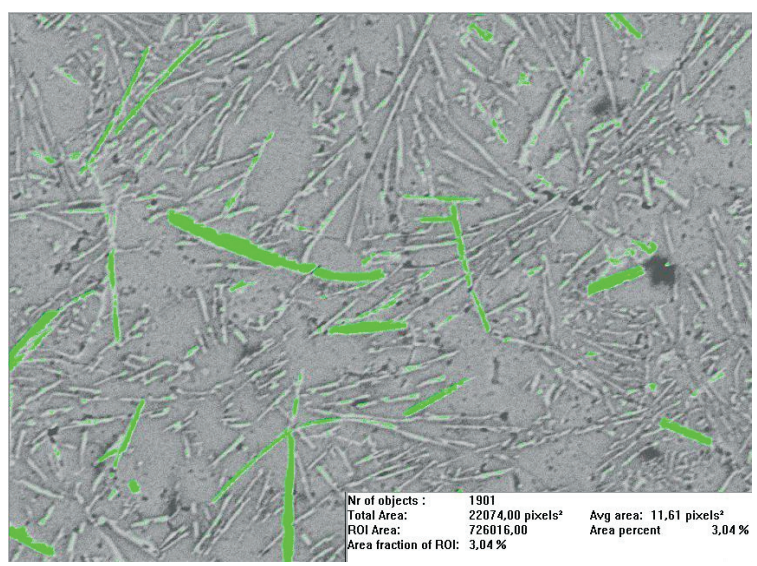

Figure 6. Intermetallic phase calculation results in SEM photograph of $\mathrm{Al}-11 \% \mathrm{Si}$ with the addition of $1.2 \% \mathrm{Fe}, 0.5 \% \mathrm{HF}$ etching.

Fraction calculation wide results on the intermetallic alloy $\mathrm{Al}-11 \% \mathrm{Si}$ is shown by the graph in Figure 6.From these graphs it is known that the higher the Fe content, the amount of intermetallic formed will be more and more

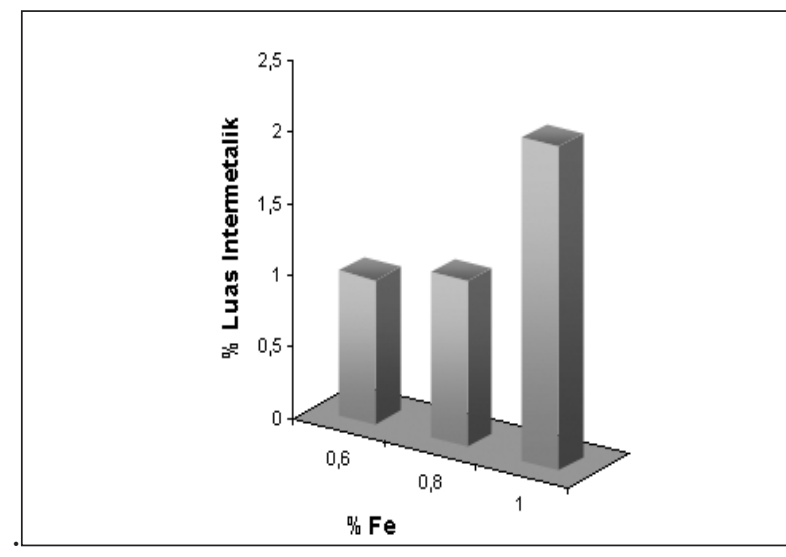

Figure 7. The relationship between percentage of Fe content and the percentage area of intermetallic formed in the $\mathrm{Al}-11 \% \mathrm{Si}$.

In the alloy $\mathrm{Al}-11 \% \mathrm{Si}$ with the addition of $0.6 \% \mathrm{Fe}$ has a total area fraction of intermetallic $1.01 \%$. While the addition of $\mathrm{Fe} 0.8 \%$ and $1 \%$ respectively have a fraction of intermetallic phases each of $1.16 \%$ and $2.26 \%$; With increasing Fe content it will multiply the area fraction of intermetallic and further means to reduce the fluidity of aluminum alloys.

\section{CONCLUSION}

From research and analysis of test results can be concluded:

Addition of $\mathrm{Fe}$ content from 0.6, 0.8 and 1.0\% in the alloy $\mathrm{Al}-11 \% \mathrm{Si}$ The higher content of $\mathrm{Fe}$ in the alloy $\mathrm{Al}-11 \% \mathrm{Si}$ will increase the size of intermetallic formed in the microstructure. Addition of $0.6 \% \mathrm{Fe}$ 
will produce intermetallic thickness and length respectively at 1.1 and $21.4 \mu \mathrm{m}$. While the addition of $0.8 \%$ will increase the size of intermetallic $\mathrm{Fe}$ to 1.6 and $32.2 \mu \mathrm{m}$. On addition of $1.0 \% \mathrm{Fe}$ intermetallic $1.6 \mu \mathrm{m}$ thick and has a length of $50.2 \mu \mathrm{m}$. Addition of these intermetallic size will reduce the value of fluidity. Increasing Fe content in the alloy also enlarge the area fraction of intermetallic formed. Intermetallic formed at most at $1.0 \%$ addition of $\mathrm{Fe}$ is equal to $2.26 \%$. On addition of 0.6 and $0.8 \% \mathrm{Fe}$ intermetallic area fraction would produce a row 1.01 and $1.16 \%$. There is a clear correlation between morphology and broad fraction of intermetallic with fluidity value (capable of flow) in the alloy $\mathrm{Al}-11 \% \mathrm{Si}$. The larger size and broad fraction will decrease the value of fluidity intermetallic.

\section{REFERENCES}

http://www.eaa.net/education/TALAT/lectures/3205.pdf; 2006

Is Prima Nanda, Bambang Suharno, Adek Tasri, Perancangan dan Pembuatan Alat uji Fluiditas
Metode Vakum, Prosiding Seminar nasional Ilmu dan teknologi material, ITS Surabaya 19 september 2006.

John A. Taylor. 2000. "The Effect of Iron in Al-Si Casting Alloys," (Brisbane: Cooperative Research Centre for Cast Metals Manufacturing (CAST), The University of Queensland, Brisbane, Australia.

Kral, M.V., McIntyre, H.R., Smillie, M.J. 2004. "Identification of intermetallic phases in a eutectic Al-Si casting alloy using electron backscatter diffraction pattern analysis". Department of Mechanical Engineering, University of Canterbury, Private Bag 4800, Christchurch, New Zealand.

Ninh Duy cuong, Cho In-Sung, Choi Jeong-Kil, Kim MyungHan, 2005. "Experimental Evaluation of Fluidity of Die Cast Aluminium Alloy“. Proceeding of the 9th Asian Foundry Congress. Hanoi-Vietnam.

Villeneuve, C., Duty H.W. and Samuel, F.H. 1999."Effect of Trace Elements on AlFeSi Characteristics and Tensile Propertiec of Al-Si-Cu (319) Foundry Alloys", Int. J. Cust Metals Res., vol. 12. in Press. 